\title{
Erratum
}

\section{Randomized Trial of Two Beta-Mimetic Drugs (Ritodrine and Fenoterol) in Acute Intra-Partum Tocolysis}

\author{
J. Gerris ${ }^{1}$, M. Thiery ${ }^{1}$, M. Bogaert ${ }^{2}$, and A. De Schaepdryver ${ }^{2}$
}

${ }^{1}$ Department of Obstetrics and ${ }^{2}$ Heymans Institute of Pharmacology, University of Gent Medical School, Gent, Belgium

Eur. J. Clin. Pharmacol. 18, 443-448 (1980)

On page 445 the legends for Figs. 1 and 2 were exchanged. They should have been printed as follows:

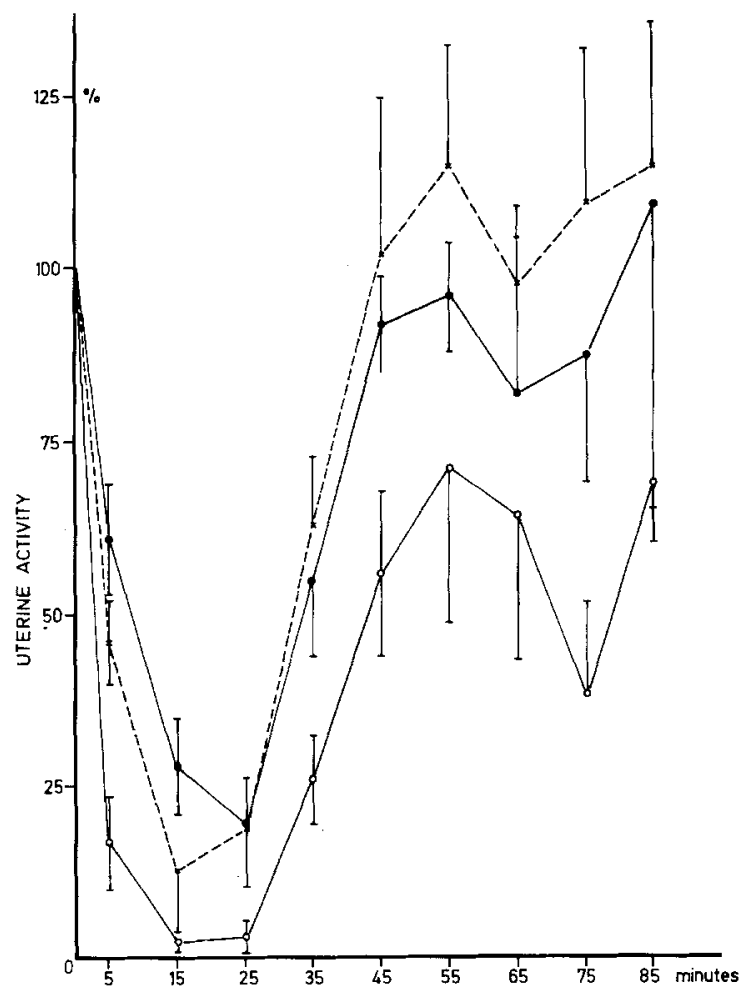

Fig. 1. Uterine activity, expressed as percentage of pre-infusion value, during and after a $30 \mathrm{~min}$ infusion of fenoterol 1,2 , or $4 \mu \mathrm{g} /$ min. Each dose was given to 4 women; mean \pm SEM

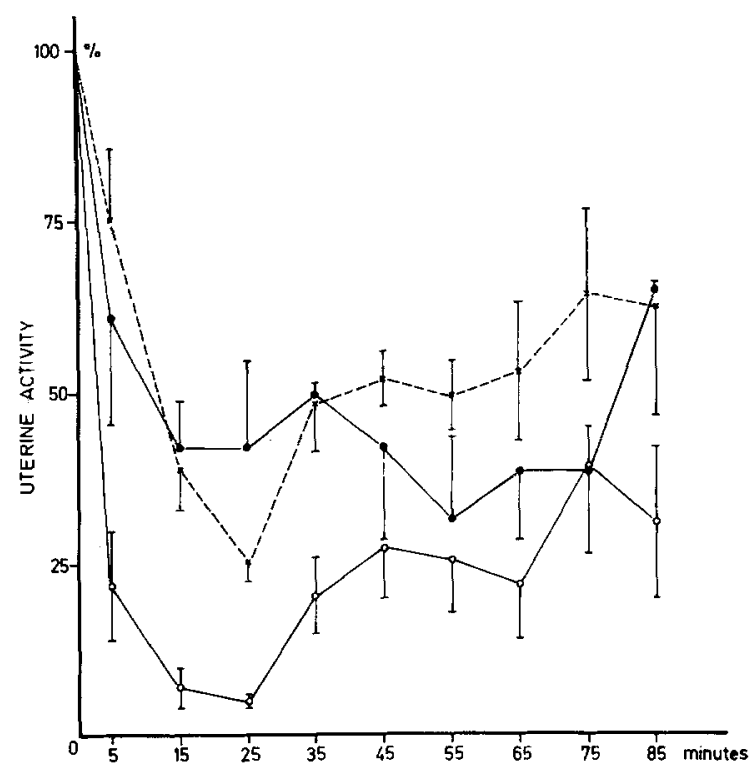

Fig. 2. Uterine activity, expressed as percentage of pre-infusion value, during and after a 30 min infusion of ritodrine 100,200 , or $400 \mu \mathrm{g} / \mathrm{min}$. Each dose was given to 4 women; mean \pm SEM

\section{Information}

The Paul Martini Prize of DM 20,000 is awarded in remembrance of Professor Paul Martini in appreciation of his contributions to the promotion of clinical therapeutical research.

The papers submitted must be self-contained, and published papers must not be older than two years. The papers should be submitted either in German or English to the Medizinisch Pharmazeutische Studiengesellschaft e.V., Bilhildisstrasse 2, D-6500 Mainz, where further information about the presentation will be available. The deadline for submission is April 28, 1981. 